\title{
Dampak Knowledge Management Terhadap Kinerja Karyawan: Sebuah Pendekatan Manajemen Islam
}

\author{
Salihah Khairawati $^{{ }^{*)} \text {, Nimas Arganingtyas }}{ }^{2)}$, Hery Sasono ${ }^{3)}$, Wijiharta Wijiharta ${ }^{4)}$ \\ ${ }^{1}$ Sekolah Tinggi Ekonomi Islam Hamfara \\ ${ }^{2,3,4}$ Program studi Manajemen Syariah Sekolah Tinggi Ekonomi Islam Hamfara \\ *Email korespondensi: salihahkh@ steihamfara.ac.id
}

\begin{abstract}
This research aims to test the influence of knowledge management consisting of three dimensions (person, procedure and technology) on employee performance. The method used in this study is a mixed method with an explanatory sequential design that combines quantitative research methods with qualitative sequentially, where in the first stage use quantitative and second stage methods with qualitative methods. With this method is expected to be obtained deeper research findings. The study respondents were 35 people wich all of them are employee. Analyze data using SPSS software version 25 with non parametric test. Non-parametric tests are performed because the data is not distributed normally. The results of the study prove that personnel affect employee kierja, job procedure concerns employee performance and technology affects employee performance. All dimensions of knowledge management demonstrate its influence on employee performance. The position of knowledge in Islam is very important, on the basis that the company also makes knowledge as an aspect that gets great attention. The company's policies and strategies are driven by the motivation of implementing Islamic values and practising knowledge
\end{abstract}

Keywords : knowledge management, kinerja karyawan, Islamic Management

Saran sitasi: Khairawati, S., Arganingtyas, N., Sasono, H., \& Wijiharta, W. (2021). Dampak Knowledge Management Terhadap Kinerja Karyawan: Sebuah Pendekatan Manajemen Islam. Jurnal Ilmiah Ekonomi Islam, 7(02), 612-620. doi: http://dx.doi.org/10.29040/jiei.v7i2.2481

DOI: http://dx.doi.org/10.29040/jiei.v7i2.2481

\section{PENDAHULUAN}

Sumber daya manusia mempunyai posisi sentral dalam mewujudkan kinerja pembangunan, yang menempatkan manusia dalam fungsinya sebagai resource pembangunan. Dalam kontek ini, harga dan nilai manusia ditentukan oleh relevansi kontruksinya pada proses produk. Kualitas manusia diprogramkan sedemikian rupa agar dapat sesuai dengan tuntutan pembangunan atau tuntutan masyarakat (Tjokrowinoto, 2012). Agar pembangunan sumber daya manusia dapat berhasil dengan baik diperlukan pendidikan dan pelatihan, sebagai investasi dalam bentuk knowledge dan skill pegawai (Manahutu et al., 2020). Pelatihan akan meningatkan kemampuan dan kompetensi pegawai dalam melaksanakan tugasnya (Abu Sinn, 2012), sehingga meningkatkan keterampilan dan produktivitas kerja, serta kepuasan pegawai di lingkungan perusahaan (Hartini et al., 2021; Robbins et al., 2018). Perusahaan yang ingin berumur panjang dan berkelanjutan, harus menempatkan sumber daya manusia yang handal sebagai human capital. Menurut teori human capital kualitas sumberdaya manusia selain ditentukan oleh kesehatan, juga ditentukan oleh pendidikan.

Bachri dan Wahyudi (2019) menyatakan kinerja karyawan yang baik dapat dilihat dari kualitas, kuantitas dan ketepatan waktu jika kinerja karyawan sudah sesuai dengan standar yang telah ditetapkan maka akan mempermudah perusahaan dalam pencapaian tujuan perusahaan. Selain kinerja karyawan, kinerja perusahaan menjadi faktor penting dalam pencapaian tujuan perusahaan kinerja perusahaan yang baik dapat dilihat dari financial performance dan operational performance.

Kemampuan organisasi untuk menggunakan dan memanfaatkan pengetahuan secara efektif sangat tergantung pada sumber daya manusianya, bagaimana menciptakan, berbagi, dan menggunakan 


\section{Jurnal Ilmiah Ekonomi Islam, 7(02), 2021, 613}

pengetahuan. Manajemen pengetahuan terlihat pengelolaan proses pembuatan, penyimpanan, akses, dan penyebaran sumber daya organisasi. Organisasi harus mempertimbangkan tujuan utama agar dapat meningkatkan kapasitas individu dan penambah pengetahuan organisasi (Antunes \& Pinheiroc, 2019). Gunjal, B. (2005) menyatakan bahwa pengetahuan merupakan sumber daya utama dan memiliki peran penting untuk pencapaian keunggulan kompetitif berkelanjutan dan pencapaian kinerja. Sebagai salah satu aset kompetitif, pengetahuan harus dimiliki setiap individu untuk dapat mengembangkan keterampilan, sehingga melalui penguasaan pengetahuan dan keterampilan individu dapat mengelola karir mereka sendiri. Oleh karenanya pengetahuan harus dikelola melalui sistem knowledge management.

Manajemen pengetahuan memiliki peranan dalam mendorong terciptanya inovasi perusahaan (Ode \& Ayavoo, 2019; Cillo et al., 2018). Manajemen pengetahuan mendorong karyawan meningkatkan produktifitas dan berfikir logis sehingga meningkatkan kreativitas dan inoatif. Agar tercapainya tujuan organisasi yang inovatif, maka perlu dibangun knowledge sharing (berbagi pengetahuan). Keuntungan dari knowledge adalah seseorang mampu menindak lanjuti atau informasi yang dapat digunakan sebagai dasar bertindak dalam pengambilan keputusan dan untuk menempuh arah atau strategi tertentu (Mohammed et al., 2017).

Sumber daya manusia Islami menurut Antonio (2012) adalah yang mempunyai tujuan hidup senantiasa menghadirkan Allah dalam setiap aktivitas hidupnya dan manusia sebagai sumber daya penggerak suatu proses produksi yang mempunyai karakteristik atau sifat-sifat mulia yang dicontohkan oleh Rasulullah SAW yang menjadi dasar dalam setiap aktivitas ekonomi dan menjadi sikap dasar manusiawi (fundamental human ethics) yang mendukung keberhasilan. Karekteristik atau sifat-sifat yang di ilhami dari shifatul anbiyaa atau sifat-sifat para nabi yaitu: shiddiq (benar), fatonah (cerdas), amanah (jujur dan dapat dipercaya), tabliq (menyeru pada kebajikan).

Dalam ayat-ayat al Qur'an terdapat sejumlah pernyataan yang menunjukkan bahwa manusia sebagai mahluk pilihan, berkualitas tinggi, kreatif dan produktif dengan sederet istilah yang dipasang, yaitu: 1) sebagai kholifah di bumi, 2) sebagai mahluk yang diunggulkan, 3) sebagai pewaris kekayaan bumi, 4) sebagai penakluk sumber daya alam, 5) sebagai pengemban amanah. Dalam sejarahnya yang panjang, memang hanya manusia saja yang telah membuktikan kesanggupannya dalam memadukan beberapa macam sumber daya untuk meningkatkan kualitas hidupnya menjadi makhluk berbudaya tinggi. Sumber-sumber daya itu adalah sumber daya alam (natural resource), sumber daya manusia (human resource) dan teknologi.

Upaya para akademisi untuk melakukan kajian mengenai manajemen pengetahuan dengan pendekatan islam mulai dilakukan sebagaimana Bakir et al. (2017) mengeksplorasi dasar-dasar manajemen pengetahuan dalam perspektif Islam, Hamzehpoor \& Javadi, (2016) melakukan kajian komperatif konsep manajemen pengetahuan dalam perspektif Islam dan Barat, Sudarti \& Zulfa (2020) menganalisis manajemen pengetahuan dan relejuisitas dalam kerangka nilai Islam. Cader et al. (2013) melakukan penelitian manajemen pengetahuan pada perbankan Islam dan konvensional di Uni Emirat Arab. Hal itu menunjukkan bahwa manajemen pengetahuan hingg kini masih menjadi suatu bidang kajian dalam ilmu manajemen yang relevan dibahas. Dari sekian banyak kajian yang ditemui penulis nampaknya masih sulit ditemukan artikel yang membahas hubungan manajemen pengetahuan dan kinerja karyawan dikaji dari aspek manajemen syariah. Penelitian ini menjembatani keterbatasan literatur serta kebutuhan peneliti akan referensi tersebut.

Tulisan ini dibagi menjadi lima bagian, pertama latar belakang menjelaskan tentang manajemen pengetahuan, tujuan penelitian, kebaharuan dalam penelitian ini. Pada bagian kedua, dijelaskan kajian literatur yang berasal dari kajian-kajian terdahulu yang pernah dilakukan pakar mengenai manajemen pengetahuan, perumusan hipotesis dan kerangka pemikiran penelitian. Pada bagian ketiga, dijelaskan tentang metode penelitian, desain penelitian populasi, sampel, tekhnik pengambilan sampel. Pada bagian keempat dalam tulisan ini menjelaskan hasil dan pembahasan, dan pada bagian akhir terdapat kelemahan penelitian serta saran penelitian lajutan.

\section{METODE PENELITIAN}

Penelitian ini menggunakan metode campuran (mixed methods) dengan desain sequential explanatory yang menggabungkan metode penelitian kuantitatif dengan kualitatif secara berurutan, di mana pada tahap pertama menggunakan metode kuantitatif dan tahap kedua dengan metode kualitatif (Sugiyono, 


\section{Jurnal Ilmiah Ekonomi Islam, 7(02), 2021, 614}

2018). Penerapan desain sequential explanatory dimulai dari pengumpulan dan analisis data kuantitatif dilanjutkan dengan pengumpulan dan analisis data kualitatif yang dibangun berdasarkan hasil awal data kuantitatif (Creswell, 2016). Penggunaan metode kuantitatif berperan untuk memperoleh data kuantitatif yang terukur dan bersifat deskriptif, sedangkan metode kualitatif berperan untuk membuktikan, memperdalam, dan memperluas data kuantitatif. Subjek penelitian ini ialah karyawan Simply Home yang bekerja di cabang Yogyakarta. Langkah pertama penelitian ini ialah mengembangkan kuesioner melalui tahap review literatur, mengkonstruksi instrumen, membuktikan validitas isi melalui kesepakatan ahli, dan uji coba lapangan. Penelitian diawali dengan pengumpulan dan analisis data kuantitatif, dilanjutkan dengan pengumpulan dan analisis data kualitatif. Hasilnya digunakan untuk memberikan penjelasan atau eksplanasi lebih lanjut mengenai fenomena yang belum dapat dijelaskan oleh hasil penelitian kuantitatif.

Jenis data yang digunakan dalam penelitian ini adalah data primer yang dikumpulkan melalui kuesioner dan wawancara. Populasi penelitian ini adalah seluruh karyawan sejumlah 35 orang dan keseluruhannya menjadi responden dalam penelitian ini. Tekhnik analisis data kuantitatif menggunakan bantuan software SPSS 25 for window. Alat uji analisis data kuantitatif dalam penelitian ini menggunakan analisis non parametrik. Statistika non parametrik adalah tidak menetapkan syarat-syarat tertentu tentang bentuk distribusi parameter populasinya. Tetapi untuk keabsahan data maka dalam penelitian ini menekankan pada hasil data lapangan untuk diuji terlebih dahulu dengan uji validitas dan reliabilitas kuesioner. Teknik analisis data kualitatif yang digunakan dalam penelitian ialah deskriptif kualitatif. Analisis data selama pengumpulan data di lapangan dengan model Miles dan Huberman yang dilakukan secara interaktif melalui proses data reduction, data display, dan verification.

\section{HASIL DAN PEMBAHASAN}

\subsection{Hasil penelitian}

Simply Homy merupakan salah satu anak perusahaan dari Simply Group yang bergerak dalam bidang penyewaan Guest House. Perusahaan ini dikelola oleh orang-orang muda yang memiliki visioner dan menjadikan nilai Islam sebagai pedoman dalam menjalankan bisnis. Sebgai sebuah organisasi yang terdiri dari orang-orang muda tentunya pembelajaran organisasi dan pengelolaan terhadap pengetahuan menjadi terbuka.

Tabel 1. Hasil Uji Validitas

\begin{tabular}{|c|c|c|c|c|}
\hline Variabel & $\begin{array}{c}\mathbf{r} \\
\text { hitung }\end{array}$ & $\begin{array}{c}\mathbf{r} \\
\text { tabel }\end{array}$ & Sig. & Ket \\
\hline \multicolumn{5}{|l|}{ Personal Knowledge $\mathrm{X}_{1}$} \\
\hline $\begin{array}{l}\text { Pengalaman kerja dan } \\
\text { profesionalitas }\end{array}$ & 0,831 & 0,334 & 0,000 & Valid \\
\hline Pengalaman Baru & 0,804 & 0,334 & 0,000 & Valid \\
\hline $\begin{array}{l}\text { Pengalaman yang } \\
\text { memperkaya } \\
\text { pengetahuan }\end{array}$ & 0,744 & 0,334 & 0,000 & Valid \\
\hline $\begin{array}{l}\text { Forum Sharing best } \\
\text { Practice atau sharing } \\
\text { knowledge }\end{array}$ & 0,655 & 0,334 & 0,000 & Valid \\
\hline $\begin{array}{l}\text { Manfaat sharing best } \\
\text { pratice atau sharing } \\
\text { knowledge. }\end{array}$ & 0,830 & 0,334 & 0,000 & Valid \\
\hline $\begin{array}{l}\text { Permasalahan dalam } \\
\text { pekerjaan }\end{array}$ & 0,831 & 0,334 & 0,000 & Valid \\
\hline \multicolumn{5}{|l|}{ Job Procedure $\mathrm{X}_{2}$} \\
\hline $\begin{array}{l}\text { Arah dan koordinasi } \\
\text { pekerjaan }\end{array}$ & 0,897 & 0,334 & 0,000 & Valid \\
\hline $\begin{array}{l}\text { Sasaran dan tujuan } \\
\text { organisasi }\end{array}$ & 0,833 & 0,334 & 0,000 & Valid \\
\hline $\begin{array}{l}\text { Tanggung jawab } \\
\text { pekerjaan }\end{array}$ & 0,825 & 0,334 & 0,000 & Valid \\
\hline $\begin{array}{l}\text { Produktivitas kerja dan } \\
\text { efisiensi waktu }\end{array}$ & 0,788 & 0,334 & 0,000 & Valid \\
\hline Pemahaman Pekerjaan & 0.837 & 0,334 & 0,000 & Valid \\
\hline $\begin{array}{l}\text { Standar SOP di setiap } \\
\text { unit }\end{array}$ & 0,872 & 0,334 & 0,000 & Valid \\
\hline \multicolumn{5}{|l|}{ Technology $\mathrm{X}_{3}$} \\
\hline Manfaat & 0,853 & 0,334 & 0,000 & Valid \\
\hline Produktivitas & 0,857 & 0,334 & 0,000 & Valid \\
\hline $\begin{array}{l}\text { Menyelesaikan pekerjaan } \\
\text { lebih cepat }\end{array}$ & 0,949 & 0,334 & 0,000 & Valid \\
\hline Kualitas output pekerjaan & 0,927 & 0,334 & 0,000 & Valid \\
\hline $\begin{array}{l}\text { Peningkatan Efektivitas } \\
\text { pekerjaan }\end{array}$ & 0,943 & 0,334 & 0,000 & Valid \\
\hline $\begin{array}{l}\text { Sarana penyebaran } \\
\text { informasi }\end{array}$ & 0,855 & 0,334 & 0,000 & Valid \\
\hline \multicolumn{5}{|l|}{ Kinerja Karyawan Y } \\
\hline $\begin{array}{l}\text { Mendukung capaian } \\
\text { Indiktaor Kinerja Utama }\end{array}$ & 0,826 & 0,334 & 0,000 & Valid \\
\hline $\begin{array}{l}\text { Mendukung capaian } \\
\text { Nilai Perilaku } \\
\end{array}$ & 0,916 & 0,334 & 0,000 & Valid \\
\hline $\begin{array}{l}\text { Mendukung kualitas hasil } \\
\text { pekerjaan }\end{array}$ & 0,945 & 0,334 & 0,000 & Valid \\
\hline Penyelesaian Pekerjaan & 0,918 & 0,334 & 0,000 & Valid \\
\hline $\begin{array}{l}\text { Berbagi dan berkerja } \\
\text { sama Kualitas }\end{array}$ & 0,837 & 0,334 & 0,000 & Valid \\
\hline
\end{tabular}




\section{Jurnal Ilmiah Ekonomi Islam, 7(02), 2021, 615}

Analisis data demografi dari responden dalam penelitian ini sejumlah 35 orang, terdiri dari 25 pria dan 10 wanita. Usia responden antara 17 sampai dengan 40 tahun. Dimana jumlah responden berusia 17 sampai 20 tahun sebanyak 30 responden dan sisanya berusia 31 sampai 40 tahun. Latar belakang pendidikan responden yang lulusan SLTA sebanyak 16 orang, lulusan perguruan tinggi 15 orang dan sisanya lain-lain.

Uji validitas digunakan untuk mengukur sah atau valid tidaknya suatu kuesioner (Imam Ghazali, 2018). Uji validitas dilakukan dengan menghukur korelasi produk momen (Moment Product Correlation/ Pearson Correlation) dengan bantuan software SPSS versi 25.

Berdasarkan data tabel di atas menunjukan bahwa semua butir pertanyaan variabel personal knowledge $\mathrm{X}_{1}$, job procedure $\mathrm{X}_{2}$, tecnhology $\mathrm{X}_{3}$, dan kinerja karyawan $\mathrm{Y}$ memiliki nilai $\mathrm{r}$ hitung lebih besar dari $r$ tabel. Maka dapat disimpulkan instrument tersebut valid. Uji reliabilitas dilakukan untuk mengetahui apakah hasil pengukuran yang dapat dipercaya. Unutk mencapai hal tersebut, dilakukan uji reliabilitas dengan metode Alpha Chronbcah's dengan menggunakan SPSS 25 for windows

Tabel 2. Hasil Uji Reliabilitas

\begin{tabular}{|l|c|c|c|}
\hline \multicolumn{1}{|c|}{ Variabel } & $\begin{array}{c}\text { Nilai } \\
\text { Kritik }\end{array}$ & $\begin{array}{c}\text { Koefisien } \\
\text { Reabilitas }\end{array}$ & Ket \\
\hline Personal Knowledge & 0,60 & 0,870 & Reliabel \\
\hline Job Procedure & 0,60 & 0,917 & Reliabel \\
\hline Tecnhology & 0,60 & 0,951 & Reliabel \\
\hline Kinerja Karyawan & 0,60 & 0,932 & Reliabel \\
\hline
\end{tabular}

Berdasarkan data tabel di atas menunjukan bahwa semua variabel personal knowledge $\mathrm{X}_{1}$, job procedure $\mathrm{X}_{2}$, tecnhology $\mathrm{X}_{3}$, dan kinerja karyawan $\mathrm{Y}$ memiliki koefisien reliabilitas lebih besar dari nilai kritis 0.60. Maka dapat disimpulkan instrument tersebut reliabel.

Untuk mengetahui apakah data terdistribusi secara normal maka dilakukan uji naromalitas.

Tabel 3. hasil Uji Normalitas

\begin{tabular}{||l|l|r|}
\hline $\mathrm{N}$ & 35 \\
\hline Normal Parameters & Mean & .0000000 \\
\cline { 2 - 3 } & Std. Deviation & .80088650 \\
\hline \multirow{2}{*}{$\begin{array}{l}\text { Most Extreme } \\
\text { Differences }\end{array}$} & Absolute & .306 \\
\cline { 2 - 3 } & Positive & .151 \\
\cline { 2 - 3 } & Negative & -.306 \\
\hline Test Statistic & .306 \\
\hline Asymp. Sig. (2-tailed) & $.000^{\circ}$ \\
\hline
\end{tabular}

a. Test distribution is Normal.

b. Calculated from data.

c. Lilliefors Significance Correction.
Berdasarkan hasil uji normalitas pada tabel Onesampel Kolmogorov -Smirnov di atas menunjukan bahwa nilai Asymp. Sig. (2-tailed) 0,000 jadi nilai sig. $(0,000)$ lebih kecil dari 0,005 . Hal ini menunjukan bahwa data yang digunakan berdistribusi tidak normal maka untuk menguji pengaruh variabel menggunakan uji non parametric.

\section{a. Uji Wilcoxon}

Uji wilcoxon bertujuan untuk menguji apakah dalam uji ini terdapat perbedaan yang sesungguhnya antara pasangan data yang diambil dari satu sampel atau dua sampel yang terikat.

Tabel 4. Hasil Uji Wilcoxon

\begin{tabular}{|l|r|r|r|}
\hline \multicolumn{4}{|c|}{ Test Statistics $^{\mathrm{a}}$} \\
\hline & \multicolumn{1}{|c|}{ Y - X1 } & \multicolumn{1}{|c|}{ Y - X2 } & \multicolumn{1}{c|}{ Y - X3 } \\
\hline Z & $-5.198^{\mathrm{b}}$ & $-5.277^{\mathrm{b}}$ & $-5.083^{\mathrm{b}}$ \\
\hline Asymp. Sig. (2-tailed) & .000 & .000 & .000 \\
\hline
\end{tabular}

a. Wilcoxon Signed Ranks Test

b. Based on positive ranks

Hasil signifikansi p-value Y-X1 sebesar 0,000 $(<0,05)$ maka Ho ditolak dan Ha diterima. Sehingga kesimpulannya personal knowledge berpengaruh signifikan terhadap kinerja karyawan. Hasil signifikansi p-value Y-X2 sebesar 0,000 $(<0,05)$ maka Ho ditolak dan Ha diterima. Kesimpulannya Job Procedure perpengaruh signifikan terhadap kinerja karyawan. Hasil signifikansi p-value Y-X3 sebesar $0,000(<0,05)$ maka Ho ditolak dan Ha diterima. Sehingga kesimpulannya Technology perpengaruh signifikan terhadap kinerja karyawan.

Hasil signifikansi p-value Y-X1 sebesar 0,000 $(<0,05)$ maka Ho ditolak dan Ha diterima. Sehingga kesimpulannya personal knowledge berpengaruh signifikan terhadap kinerja karyawan. Hasil signifikansi p-value Y-X2 sebesar $0,000(<0,05)$ maka Ho ditolak dan $\mathrm{Ha}$ diterima. Kesimpulannya Job Procedure perpengaruh signifikan terhadap kinerja karyawan. Hasil signifikansi p-value Y-X3 sebesar $0,000(<0,05)$ maka Ho ditolak dan Ha diterima. Sehingga kesimpulannya Technology perpengaruh signifikan terhadap kinerja karyawan.

Hasil signifikansi p-value Y-X1 sebesar 0,000 $(<0,05)$ maka Ho ditolak dan Ha diterima. Sehingga kesimpulannya personal knowledge berpengaruh signifikan terhadap kinerja karyawan. Hasil signifikansi p-value Y-X2 sebesar 0,000 $(<0,05)$ maka Ho ditolak dan Ha diterima. Kesimpulannya Job Procedure perpengaruh signifikan terhadap kinerja karyawan. Hasil signifikansi p-value Y-X3 sebesar $0,000(<0,05)$ maka Ho ditolak dan $\mathrm{Ha}$ diterima. 
Sehingga kesimpulannya Technology perpengaruh signifikan terhadap kinerja karyawan.

\section{b. Uji Friedman}

Uji Friedman ini bertujuan untuk menguji kesamaan pengaruh perlakuan tetap dari dua atau lebih populasi.

Tabel 5. Hasil Uji Friedman

\begin{tabular}{|l|r|}
\hline \multicolumn{2}{|c|}{ Ranks } \\
\hline & \multicolumn{1}{|c|}{ Mean Rank } \\
\hline $\mathrm{X} 1$ & 2.84 \\
\hline $\mathrm{X} 2$ & 3.27 \\
\hline $\mathrm{X} 3$ & 2.79 \\
\hline $\mathrm{Y}$ & 1.10 \\
\hline
\end{tabular}

\begin{tabular}{|l|l|}
\hline \multicolumn{2}{|l|}{ Test Statistics } \\
\hline $\mathrm{N}$ & 35 \\
\hline Chi-Square & 76.682 \\
\hline Df & 3 \\
\hline Asymp. Sig. & .000 \\
\hline a. Friedman Test \\
\hline
\end{tabular}

Pada tabel test statistic terlihat bahwa besaran Chi Square $=76.682$ dan Asymp. Sig. 0.000. Hasil uji signifikansi Chi Square menunjukan bahwa sig $<0.05$ sehingga dapat disimpulkan bahwa X1: Personal Knowledge, X2 : Job Procedure dan X3: Technology yang ada memberikan pengaruh terhadap kinerja karyawan. Dari hasil uji Friedman diketahui bahwa X2: Job Procedure mendapat pengaruh paling tinggi terhadap kinerja karyawan, disusul X1: Personal Knowledge, kemudian X3: Technology.

\subsection{Pembahasan}

Knowledge Management didefinisikan sebagai pengelolahan knowledge perusahaan dalam menciptakan nilai bisnis (business value) dan menghasilkan keunggulan kompetitif yang berkesinambungan dengan mengoptimalkan proses penciptaan, pengkomunikasian, dan pengaplikasian semua knowledge yang dibutuhkan dalam rangka pencapaian tujuan bisnis (Razimi et al., 2014). Knowledge management mempunyai variabel yaitu Personal Knowledge, Job Procedure dan Technology. Dalam variabel personal knowledge $\left(\mathrm{X}_{1}\right)$ indikatornya adalah pengalaman kerja, profesional, pengalaman baru, pengalaman yang memperkaya pengetahuan, forum sharing best practice atau knowledge sharing, manfaat sharing best practice atau knowledge sharing dan menyelesaikan permasalahan dalam pekerjaan.
Dari hasil wawancara yang dilakukan kepada sejumlah karyawan dari mereka pengetahuan personal sangat penting dan hal tersebut berkorelasi dengan pencapaian kinerja mereka. Seperti halnya bagimana suatu pengetahuan bisa diperoleh dari pengalaman kerja selama berturut-turut ketika mereka bekerja. Pengalaman itu disimpan, dan digunakan kembali ketika mereka melakukan pekerjaan yang sama. Selain itu pengalaman itu seringkali dibagikan kepada rekan kerja dalam sebuah forum yang diselenggarkan perusahaan. Misalnya ada karyawan yang mengikuti pelatihan, setelah itu di kemudian hari karyawan tersebut dapat berbagi kepada teman-temannya mengenai pengetahuan yang diperoleh, dengan demikian proses pemerataan dan peningkatan pengetahuan di kalangan karyawan dapat terjadi.

Menurut karyawan, pengalaman yang diperoleh dari rekan kerja sebagai suatu pengetahuan. Pengetahuan bagi karyawan seringkali membantu mereka dalam penyelesaian pekerjaan mereka, baik penyelesian pekerjaan menjadi lebih cepat atau penyelesaian pekerjaan menjadi lebih baik. Dari hasil wawancara tersebut dapat memperkuat bukti bahwa kinerja karyawan dipengaruhi oleh pengetahuan luas yang dimiliki karyawan dan hal tersebut berdampak pada kemampuan menyelesaikan permasalahan pekerjaan menjadi lebih baik, hal ini sebagaimana penelitian yang dilakukan oleh Cader, et.al (2013) bahwa pegetahuan dibagikan melalui kegiatan formal dan informal pada Bank Syariah di UEA antara lain melalui e-mail, intranet and extranet, discussion boards, training, and meetings

Islam memandang bahwa ilmu merupakan dasar penentuan martabat seseorang dalam kehidupan, dimana penambahan ilmu akan meningkatkan pemahaman seseorang terhadap berbagai dimensi kehidupan (Abu Sinn, 2012). Setiap muslim diwajibkan menuntut ilmu sebagaimana disebutkan dalam hadits bahwa Rasulullah Shallahu alaihi Wasallam bersabda: "Menuntut ilmu merupakan kewajiban bagi setiap muslim."(Hadits sahih, diriwayatkan dari beberapa sahabat diantaranya: Anas bin Malik, Ibnu Abbas, Ibnu Umar, ali bin abi Thalib, dan Abu Sa'id Al-Khudri Ra. Sahih al-jami: 3913).

Pengetahuan yang luas dalam pekerjaan dapat digolongkan fathonah dan menyampaikan informasi atau pengetahuan dapat digolongkan dengan tabligh. Data yang diperoleh dari wawancara terhadap responden bagaimana personal knowledge diterapkan dalam perusahaan antara lain bahwa pengalaman kerja 
dapat menjadi suatu pengetahuan baru, pengetahuan yang dimiliki dapat mendorong karyawan memahami pekerjaan, mendapatkan tambahan pengetahuan baru dari pekerjaanya, terdorong membuat inovasi baru dengan pengetahuan yang dimiliki, sharing pengetahuan dengan teman sekantor, dan dapat menyelesaikan permasalahan pekerjaan lebih baik, berdasarkan wawancara tersebut mengindikasikan bahwa fathonah dan tabligh dapat memberikan pengaruh kepada para karyawan untuk meningkatkan kinerja. Para karyawan menganggap bahwa kinerja dapat didasari oleh fathonah dan tabligh dari pengetahuan yang ada di dalam diri mereka.

Job Procedure $\left(\mathrm{X}_{2}\right)$ indikatornya adalah arahan koordinasi, sasaran tujuan organisasi, tanggungjawab pekerjaan, produktivitas dan efesiensi kerja, pemahaman pekerjaan, dan adanya Standar Operasional Procedure (SOP) di setiap unit. Dari hasil wawancara kepada responden mengenai $J o b$ Procedure $\left(\mathrm{X}_{2}\right)$ mayoritas menyatakan dapat menyelesaikan pekerjaan sesuai dengan target perusahaan dengan diterapkannya job procedure di perusahaan. Prosedur kerja yang sudah dipelajari akan menjadi acuan bagi karyawan dalam melaksanakan tugas, tentunya dengan hal itu maka menjalankan pekerjaan jauh lebih mudah bagi karyawan. Dari data tersebut dapat disimpulkan bahwa kinerja karyawan dipengaruhi oleh diterapkannya Job Procedure dan dengan adanya hal tersebut mendororng karyawan menyelesaikan pekerjaan sesuai target perusahaan lebih cepat dan bahkan lebih cepat dari target perusahaan. Dalam menyelesaikan pekerjaan yang tepat waktu harus tetap berpegang teguh pada norma moral dan akhlak dan keridhoan Allah SWT sebagai tolak ukur dalam menyelesaikan pekerjaan. Dalam hal ini Islam selalu mengajarkan agar manusia hidup efesiensi atau tidak berlebih-lebihan, atau tidak melewati batas tetapi haruslah seimbang dan juga Islam menganjurkan manusia untuk dapat melakukan pekerjaan mereka dengan di dasari oleh amanah dan siddiq dari kepercayaan yang timbul didalam dirinya.

Amanah dan siddiq berpengaruh positif dan signifikansi terhadap kinerja karyawan Simply Homy Guest House Yogyakarta dengan responden dari ke enam pertanyaan mengenai koordinasi dengan pihak yang terkait, memahami sasaran dan tujuan organisasi, adanya rasa tanggungjawab, menyelesaikan pekerjaan tepat waktu dan adanya SOP di setiap unit, rata-rata menjawab setuju. Hal ini mengindikasikan bahwa amanah dan siddiq dapat memberi pengaruh kepada para karyawan untuk meningkatkan kerja. Para karyawan mengangap bahwa kinerja dapat didasari oleh amanah dan siddiq dari kepercayaan yang timbul didalam dirinya. Kepercayaan atas pekerjaan yang diberikan selalu terjaga, sehingga saat kepercayaan itu ada dalam dirinya, maka membuat ketenangan hati dan rasa tanggungjawab, dan jujur dalam menyelesaikan setiap pekerjaan yang diterimanya. Dengan demikian timbul semangat untuk selalu bekerja dan kinerjapun tentunya akan meningkat. Sehingga amanah dan siddiq tersebut benar-benar terlaksanakan. Hal ini sejalan dengan pendapat Antonio (2012) bahwa rasulullah merupakan teladan dalam bentukan karakter yang baik, salah satunya adalah amanah dan siddiq. Amanah merupakan jujur/terpercaya, bertanggungjawab dan siddiq merupakan menyeru dalam kebijakan.

Technology $\left(\mathrm{X}_{3}\right) \quad$ indikatornya adalah produktvitas, manfaat, menyelesaikan lebih cepat, kualitas ouput pekerjaan, peningkatan efektivitas pekerjaan dan sarana penyebaran informasi. Dari hasil penelitian dalam technology $\left(\mathrm{X}_{3}\right)$ jawaban paling dominan adalah setuju yang terdapat pada item pertanyaan empat dan enam, yaitu kualitas output dan sarana penyebaran informasi lebih mudah dengan adanya technology yang ada di perusahaan, yaitu sebanyak 36 responden dari masing-masing item pertanyaan. Dari data tersebut dapat disimpulkan bahwa kinerja karyawan dipengaruhi oleh technology yang disediakan perusahaan terkhusus dalam hasil output dan penyebaran informasi antar unit kerja.

Islam mengajarkan seorang muslim agar menghargai ilmu pengetahuan dan keahlian, serta mewajibkan kepada siapa saja untuk menuntut ilmu. Manusia diperintahkan menuntut ilmu, karena dengan ilmu pengetahuan bisa mencapai cita-cita apa yang diinginkan baik dunia maupun akhirat, perkembangan ilmu sains dan technology juga sangat penting untuk membangun peradaban yang kuat dan tangguh. Sebagaimana halnya dahulu para khalifah mendorong kaum muslim untuk menciptakan technology dan membuat karya ilmiah guna mengembangkan dan memanfaatkan SDA. Biografi para ulama terdahulu menggambarkan bahwa mereka mempelajari ilmuilmu Islam dan mempelajari pengetahuan umum (Widjajakusuma \& Yusanto, 2002). Dalam surat ArRahman:33 yang artinya: "Hai jamaah jin dan manusia, jika kamu sanggup menembus (melintasi) penjuru langit dan bumi, maka lintasilah, kamu tidak dapat menembusnya melainkan dengan kekuatan". 


\section{Jurnal Ilmiah Ekonomi Islam, 7(02), 2021, 618}

Syeikh Imam Ashaari Muhammad At Tamimi seperti dalam Effendi \& Puspita (2007) menegaskan bahwa semua aktifitas keseharian kita termasuk mengkaji dan mengembangkan sains dan teknologi dapat bernilai ibadah bahkan perjuangan di sisi Allah bila memenuhi 5 syarat ibadah: niat yang benar, pelaksanaannya benar-benar di atas landasan syariat atau aturan Allah, perkara atau subyek yang menjadi tumpuan untuk dilaksanakan atau dikaji itu mestilah mendapat keridhaan Allah, subyek yang paling utama mestilah suci agar benar-benar menjadi ibadah kepada Allah, natijah (hasil) mesti baik karena merupakan pemberian Allah kepada hamba-Nya, tidak melalaikan pelaksanaan ibadah.

Agama dan ilmu pengetahuan technology merupakan dua sisi yang tidak dapat dipisahkan satu sama lain. Ilmu adalah sumber technology yang mampu memberikan penemuan-penemuan baru, ideide baru dalam menciptakan inovasi kerja. Dengan kemudahan-kemudahan yang ditawarkan technology juga harus mampu mendorong karyawan untuk berkembang lebih maju, bekerja sesuai dengan nilainilai agama islam tidak hanya sebagai pemuas kebutuhan semata.

Technology yang semakin canggih dapat menjadikan salah satu media pengetahuan tambahan yang baik buat para sumber daya manusia untuk menambah pengetahuan dan menyebarkan informasi pekerjaan dalam meningkatkan kinerja. Technology internet dalam hal pengetahuan hal yang baik dalam bidang peningkatan kinerja pekerjaan yang dimiliki oleh sebagian karyawan muslin penguasaan tekhnologi dapat dikaitkan dengan sifat fathonah.

Bagimana fathonah berpengaruh positif dan signifikansi terhadap kinerja karyawan Simply Homy Guest House Yogyakarta dari wawancara responden bahwa tekkhnologi yang dipakai oleh perusahaan selama ini cukup dapat mendukung produktvitas kerja, manfaat yang dirasakan cukup banyak, tekhnologi yang digunakan perusahaan membantu karyawan menyelesaikan pekerjaan lebih cepat, kualitas ouput atau hasil kerja menjadi lebih baik, efektivitas pekerjaan meningkat dan sarana penyebaran informasi. Hal ini mengindikasikan bahwa fhathanah dapat memberi pengaruh kepada para karyawan untuk meningkatkan kerja. Para karyawan mengangap bahwa kinerja dapat didasari oleh fathonah dari pemahaman, mengerti dan menghayati secara mendalam segala hal yang menjadikan tugas dan kewajiban.
Jika seorang karyawan memiliki kesadaran akan kewajiban sebagai seorang muslim yang bertaqwa. Sesunggguhnya karyawan sudah memiliki sifat dan karakter sumber daya insani. Maka, karyawan akan menyadari, menjalankan tugas, dan sebagai karyawan yang bekerja $\mathrm{d}$ isuatu perusahaan dengan baik, dengan penuh tanggungjawab, dengan penuh amanah, dan dapat membedakan mana yang baik mana yang buruk, karena manusia mempunyai unsur yang lebih lengkap dan diberi akal untuk berfikir, sehingga bebas menentukan jalan mana yang akan dipilih, sehingga jika semua itu dilaksanakan dengan baik maka tercapailah kesejahteraan bersama dalam suatu perusahaan. Jika karyawan mamandang suatu pekerjaan yang dilakukan adalah amal yang terkait dengan iman, maka iya mampu memilih kerja yang sesuai dengan iman, akan terjamin mutunya sebagai amal saleh. Islam merupakan agama yang mendorong umatnya untuk berfikir kreatif dan produktif. Sedangkan orang-orang yang berfikir produktif bisa memiliki kinerja yang tinggi.

\section{KESIMPULAN}

Hasil uji validitas dan reliabilitas terhadap kuesioner dalam penelitian ini diperoleh hasil bahwa seluruh butir pertanyaan valid dan reliable. Hasil uji normalitas pada tabel One-sampel Kolmogorov Smirnov menunjukkan bahwa data yang digunakan tidak berdistribusi normal, sehingga pengujian data dilakukan dengan menggunakan uji non parametric. Berdasarkan hasil uji Wilcoxon yang bertujuan untuk menguji apakah dalam uji ini terdapat perbedaan yang sesungguhnya antara pasangan data yang diambil dari satu sampel atau dua sampel yang terikat. Hasil Uji Wilxocon menegaskan bahwa hipotesis dari ketiga variable personal knowledge, job procedur dan technology terbukti. Artinya hipotesa Personal Knowledge (X1), Job Procedure (X2) dan Technology (X3) berpengaruh terhadap kinerja karyawan terbukti. Uji Friedman bahwa variabel independen Personal Knowledge (X1), Job Procedure (X2) dan Technology (X3) berpengaruh terhadap variabel dependen Kinerja Karyawan (Y). Secara parsial Personal Knowledge (X1) berpengaruh terhadap Kinerja karyawan. Job Procedure (X2) berpengaruh karena terhadap kinerja karyawan. Sedangkan Technology (X3) berpengaruh terhadap kinerja karyawan. Dari data yang diperoleh menegaskan bahwa job procedur merpakan variable yang paling dominan dalam mempengaruhi kinerja karyawan. 
Dalam pandangan Ekonomi Islam melihat 3 variabel yang melibatkan karyawan Simply Homy Gest House Yogyakarta dalam kinerja karyawan, mereka melaksanakan tugas sesuai dengan aturan berlaku dalam islam dan juga sesuai dengan Core Value Simply Challenger (F.A.S.T) yang menjadi dasar Simply Homy Guest House dalam capaian kinerja. Islam mengajarkan untuk selalu terus mencari ilmu pengetahuan, islam juga menempatkan menuntut ilmu adalah kewajiban kepada siapa saja terkhusus umat muslim yang akan menjadi tonggak perubahan peradaban yang tangguh dan kuat. Mengembangkan ilmu pengetahuan yang berlanjut dapat membantu kita untuk melakukan pekerjaan yang baik sehingga sehingga menghasilkan kinerja yang baik pula sesuai dengan nilai-nilai islam seperti Fathonah, Amanah, Siddiq, dan Tabligh.

Penelitian ini memiliki beberapa keterbatasan. Pertama, jumlah responden yang terbatas dan hanya bidang usaha jasa penyewaan homestay, sehingga tidak dapat digeneralisir untuk jenis lain dari perusahaan yang sama. Di masa yang akan datang penelitian diharapkan dapat menggunakan responden yang lebih banyak untuk bidang usaha yang berbeda. Kedua, penelitian ini terbatas hanya menguji variable knowledge management, pada penelitian selanjutnya peneliti dapat menambahkan variable lain yang diduga memiliki hubungan pengaruh terhadap kinerja karyawan.

\section{REFERENSI}

Abu Sinn, A. I. (2012). Manajemen Syariah: Sebuah Kajian Historis dan Kontemporer (Judul asli: Al Idarah fil Islam). Rajawali Press.

Alawamleh, M., Ismail, L. B., Aladwan, K., \& Saleh, A. (2017). Article information:

Antonio, S. (2012). Kepemimpinan dan Pengembangan Diri: Ensiklopedia Muhammad SAW The Super Leader. Super Manajer Jilid 1. Tazkia Publishing.

Antunes, H. de J. G., \& Pinheiroc, P. G. (2019). Linking knowledge management, organizational learning and memory Helder. Journal of Innovation \& Knowledge. https://doi.org/10.1016/j.jik.2019.04.002

Arifandi, M., \& Presilawati, F. (2019). Pengaruh Personal Knowledge,Job Procedure Dan Technology Terhadap Kinerja Pegawai Pada Dinas Sosial Aceh. Jurnal Ilmiah Manajemen Muhammadiyah Aceh (JIMMA), 9(2), 133-168.
Bachri, C., \& Wahyudi. (2019). Pengaruh Personal Knowledge, Technology Literacy Dan Job Procedure Terhadap Kinerja Karyawan Pada Departemen It Bank Danamon. Jurnal AKRAB JUARA, 4(4), 1.

Bader, R. M., Obeidat, Y., \& Tarhini, A. (2016). Journal of Management Development. Journal of Management Development, 35(5). https://doi.org/10.1108/jmd.2006.02625haa.001

Bakir, M., Yaakub, H., \& Othman, K. (2017). The Foundation of Islamic Knowledge Management Practices. $\quad$ https://doi.org/10.1007/978-3-31939679-8

Cader, Y., Neill, K. K. O., Ali, A., Amena, B., Bakheet, A., Shouq, A., Hussain, B., Cader, Y., Neill, K. K. O., Ali, A., Amena, B., Bakheet, A., Shouq, A., Hussain, B., Cader, Y., Neill, K. K. O., Blooshi, A. A., Ali, A., Al, B., ... Ali, F. G. (2013). Knowledge management in Islamic and conventional banks in the United Arab Emirates. https://doi.org/10.1108/01409171311314996

Cillo, V., Rialti, R., Bertoldi, B., \& Ciampi, F. (2018). Knowledge management and open innovation in agri-food crowdfunding. https://doi.org/10.1108/BFJ-07-2018-0472

Creswell, J. W. (2016). Research Design: Pendekatan Metode Kualitatif, Kuantitatif dan Campuran. Pustaka Pelajar.

Effendi, A. R., \& Puspita, G. (2007). Membangun Sains dan Teknologi Menurut Kehendak Tuhan. Giliran Timur.

G., B. (2005). Knowledge Management: Why Do We Need It For Corporates. Malaysian Journal of Library \& Information Science, 10(2), 37-50.

Hamzehpoor, M., \& Javadi, M. (2016). Explaining and Comparing Theoretical Foundations of Knowledge Management from Point of View of Islam and Wes. The Interdisciplinary Quarterly of Fundamental Researches on Humanities, 2(3), 31-58.

Hartini, Ramaditya, M., Irwansyah, R., Putri, D. E., Ramadhani, I., Wijiharta, Bairizki, A., Firmadani, F., Febrianty, Suandi, Julius, A., Pangarso, A., Satriawan, D. G., Indiyati, D., Sudarmanto, E., Panjaitan, R., Lestari, A. S., \& Farida, N. (2021). PERILAKU ORGANISASI. Widina Bhakti Persada.

Huber, G. P. (1991). Organizational Learning: The Contributing Processes and the Literatures. August 2015. 
Imam Ghazali. (2018). Aplikasi Analisis Multivariate dengan Program IBM SPSS 25. BP Universitas Diponegoro.

Iskandar, A., \& Subekan, A. (2018). Pengaruh Personal Knowledge, Job Procedure Dan Technology Terhadap Kinerja Pegawai Organisasi Publik. Jurnal Riset Manajemen Sains Indonesia (JRMSI), 9(2), 168-192.

Lestari, P. S., \& Widiartanto. (2017). Pengaruh Personal Knowledge, Job Procedure Dan Teknologi Terhadap Kinerja Karyawan ( Studi Kasus Penerapan Knowledge Management pada PT . Nasmoco Karangjati Motor ). Jurnal Ilmu Administrasi Bisnis, 6(1), 156-163.

Manahutu, M. A., Merung, Y. A., Hasbi, I., Enas, U., Satriawan, D. G., Wijiharta, Lasmono, S., Irwansyah, R., Zulfikar, R., Kusumastuti, D., Maulida, I. S. R., Kustini, E., \& Mahmud, A. (2020). Manajemen Sumber Daya Manusia (Sebuah strategi, perencanaan dan pengembangan). Widina Bhakti Persada.

Michael Polanyi. (1966). No TitleThe Logic of The Tacit Inference. Philosophy, 41(155).

Mohammed, A., Elrehail, H., \& Ahmad, M. (2017). Journal of Innovation and organizational performance. $1-15$. https://doi.org/10.1016/j.jik.2017.07.003

Mulyadi. (2014). Sistem Akuntansi. Salemba Empat.

Nuryana, Z. (2018). Pemanfaatan teknologi informasi dalam pendidikan agama islam. Jurnal TAMADDUN, 19(1), 75-86.

Nuskiya, A. F. (2018). The Effect of Information Technology on Employees 'Performance in the Banking Industry in Sri Lanka . Empirical Study Based on the Banks in Ampara District. 10(16), 47-52.

Ode, E., \& Ayavoo, R. (2019). The mediating role of knowledge application in the relationship between knowledge management practices and firm innovation. Suma de Negocios. https://doi.org/10.1016/j.jik.2019.08.002

Pirngadi, Y., Hasanuddin, B., \& DPS, M. (2017). Effects of Human Capital , Information Technology and Financial Investment on $t$ he Employees' Performance and Competitiveness of the Banking Industry in Indonesia. Scientific Research Journal (SCIRJ), 5(10), 58-66.
Raja, F. U., \& Ansari, S. (2018). Social Networking Applications And Employees' Performance. Journal of Social Sciences and Media Studies, 2(1).

Razimi, M. S. B. A., Noor, M. M., \& Daud, N. M. (2014). The Concept of Dimension in Human Resource Management from Islamic Management Perspective Arshad Ayub Graduate Business School ,. Middle-East Journal of Scientific Research, 20(9), 11751182.

https://doi.org/10.5829/idosi.mejsr.2014.20.09. 12513

Robbins, S. P., Judge, T. A., \& Breward, K. E. (2018). Essential of Organizational Behaviour. Pearson.

Sudarti, K., \& Zulfa, M. (2020). Knowledge Management and Religiosity: A Conceptual Development of Islamic Vanguard Spirit. 1, 939-945. https://doi.org/10.1007/978-3-03022354-0

Sugiyono. (2018). Metode Penelitian Manajemen. Alvabeta.

Tjokrowinoto, M. (2012). Pembangunan Dilema dan Tantangannya. Pustaka Pelajar.

Wassem, M., Baig, S. A., Abrar, M., Hashim, M., Ziaur-rehman, M., Awan, U., Amjad, F., \& Nawab, Y. (2019). Impact of Capacity Building and Managerial Support on Employees Performance: The Moderating Role of Employees , Retention. https://doi.org/10.1177/2158244019859957

Widjajakusuma, M. K., \& Yusanto, M. I. (2002). Pengantar Manajemen Syariat. Khoirul Bayan.

Zarkowi, R., \& Widiartanto. (2016). Pengaruh Personal Knowledge , Organizational Learning, Dan Teknologi Terhadap Kinerja Karyawan Hotel Patra Jasa Semarang. Jurnal Ilmu Administrasi Bisnis, 5(3), 146-155. 
Jurnal Ilmiah Ekonomi Islam, 7(02), 2021, 621 